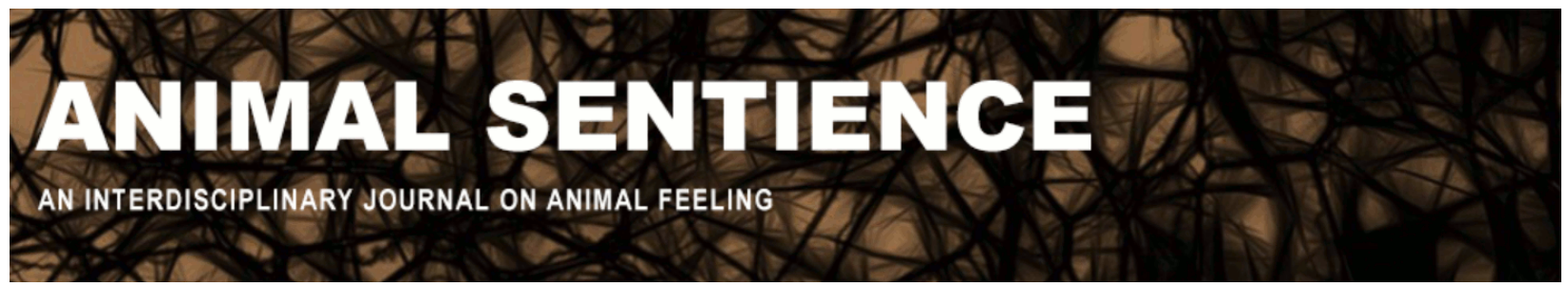

Batavia, Chelsea (2020) Is anthropocentrism really the problem?. Animal Sentience 27(20)

DOI: $10.51291 / 2377-7478.1557$

Date of submission: 2020-02-15

Date of acceptance: 2020-02-19

(c)

This article has appeared in the journal Animal

Sentience, a peer-reviewed journal on animal

cognition and feeling. It has been made open access,

free for all, by WellBeing International and deposited

in the WBI Studies Repository. For more information,

please contact

wbisr-info@wellbeingintl.org.

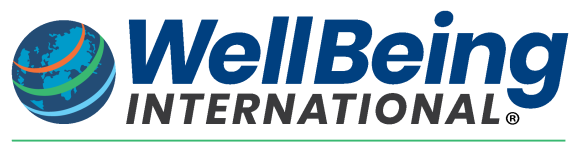

SOLUTIONS FOR PEOPLE, ANIMALS AND ENVIRONMENT 


\title{
Is anthropocentrism really the problem?
}

Commentary on Treves et al. on Just Preservation

\author{
Chelsea Batavia \\ Department of Forest Ecosystems and Society \\ Oregon State University
}

\begin{abstract}
Treves et al. (2019) highlight what they consider soft forms of anthropocentrism in the practice and philosophy of conservation, e.g., when even professed non-anthropocentrists assert the precedence of human over nonhuman interests. I consider a few philosophical cases for maintaining human precedence, but ultimately offer a more psychological explanation: our explanations for why humans take precedence serve to reduce dissonance and discomfort, which arise because the norms and institutions of society often compel us to act in ways that violate our moral responsibilities to nonhuman beings.
\end{abstract}

Chelsea Batavia is a post-doctoral researcher at Oregon State University. Her research integrates social scientific and philosophical methods, and concentrates on ethical aspects of environmental management and conservation. $\underline{\text { Website }}$

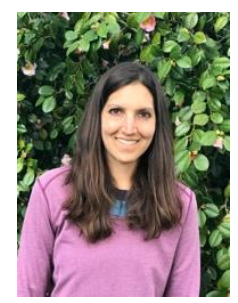

Treves et al. (2019) address some of the core problems in conservation ethics, asking how to achieve justice across scales, species, and levels of biological organization. Their discussion of the nuances within the general classes "human" and "nonhuman" is important and insightful, and has clearly provoked extensive reflection and dialogue. Many of the commentaries in this journal have addressed the potential for conflict between duties to individuals and duties to collectives (e.g., Bergstrom 2019; Paez 2020). These are topics I also find fascinating and perplexing, especially as they have surfaced in recent debates around compassionate conservation (e.g., Wallach et al. 2018; Hayward et al. 2019; Johnson et al. 2019). But for the time being, I would like to return to the multi-species terrain and consider the broad classes "human" and "nonhuman." The question I want to explore is: when hard cases arise, forcing a choice between human and nonhuman interests, why do we (nearly) always insist human interests should win?

Treves et al. raise this question in their critique of the anthropocentric underpinnings of conservation. They highlight Vucetich et al.'s (2018) Non-Anthropocentric (NA) Principle and the associated qualification that, "While the NA principle is unequivocally non-anthropocentric, it prioritizes human well-being." First, it is not my understanding that Vucetich et al. meant "prioritize human well-being" in the hierarchical sense that human wellbeing takes categorical precedence over everything else. I believe they simply meant to state that human wellbeing is a priority (among others), a proposition with which I can easily agree. Nonetheless, I appreciate and to some extent share the frustration expressed by Treves et al., and echoed in commentary by Correia Caeiro (2020), regarding what appear to be overt or at times thinly veiled forms of anthropocentrism that insist nonhumans count, and deny some fundamental hierarchy of 
existence, yet still maintain a pre-eminent position for human beings. I myself am guilty of perpetuating such views. In one moment, I assert the intrinsic value and direct moral standing of nonhuman entities, and in the next qualify those claims with the assurance that human interests would and should never be sacrificed for equivalent nonhuman interests.

Even the leading figures of the animal welfare and animal rights movement, Peter Singer and Tom Regan, have their own contingency clauses to justify why we should prioritize humans over nonhumans in situations of conflict (all other morally relevant factors equal). At the risk of grossly oversimplifying I would summarize the main points thus: humans have a capacity for cognitive and social complexity - as well as a more complex experience of suffering - than other life forms; so when the hard tradeoff scenario arises, more is at stake in human life and human wellbeing (Regan 1983; Singer 2011). I am not a scientist, but even just based on the commentaries presented here (e.g., Alexander 2019; Dulaney 2020), it seems to me that claiming exemptions for humans based on their exceptional capacities is tenuous, at least with regard to some nonhuman animals. More important, the impulse to treat human abilities as a quasiobjective measure of moral status is problematic, as it comes with a built-in anthropocentric (and rationalist/masculinist) bias (Plumwood 1993).

So perhaps we should look past (white, male) canonical environmental ethics to seek explanations in alternative literatures. A feminist environmental ethic, for example, might emphasize the moral responsibilities that arise from and are enacted in relationships of care (Warren 1990; Plumwood 1993; Taylor 2018). On this reasoning it might be suggested that, although humans are not abstractly or categorically superior to nonhumans (Chapman \& Huffman 2018), in lived experience we form closer bonds with other humans, and these bonds form the grounds for deeper moral concern. Yet this seems strange, as on the same account, I would feel justified in rescuing a familiar dog from a burning building before I rescued an unknown human. I am also not convinced I would acknowledge higher moral obligations to an unknown human than to an unknown badger. The point is, recognizing relation and care as the roots of moral obligation does not necessarily mean humans should or would come out on top in hard cases.

My hypothesis is that the preeminence placed on human beings does not necessarily reflect the overt denial that nonhuman entities have intrinsic value, as is implied in the word "anthropocentrism," or even that nonhuman entities are accorded lower moral status. Instead, I think our philosophical explanations may be psychological coping mechanisms, deployed to reduce the dissonance of being unable to fulfill all our moral requirements. Psychological research has demonstrated that moral reasoning can be biased by motivations to reach a desirable conclusion (Ditto et al. 2009; Uhlmann et al. 2009; Graça et al. 2016; Piazza and Loughnan 2016). I think a similar process may be at work here.

Consider a dilemma where I have mutually incompatible responsibilities to two entities, both of whom I regard, ethically, as persons (e.g., a human and an elephant). For various reasons (political, social, emotional), it is probably easier to override the interests of the elephant than the human being. (I remain silent as to whether this is also morally appropriate.) So I prioritize the human being. At this point, rather than confronting the uncomfortable realization that I have failed to act on the full breadth of my moral responsibilities, perhaps I will instead deny those responsibilities that I cannot uphold. Thus, I produce reasons to explain why it is right to prioritize humans over elephants (and nonhuman beings in general). 
In short, I suggest that because we cannot act in ways that reflect everything we value, we shift our notions of value to better reflect our actions. My guess is that most conservationists are neither anthropocentrists nor ecofascists. If we lived in a world that allowed us to do so, I think (or I would like to think) most of us would recognize and honor a moral community teeming with diversity: humans, nonhumans, present, future, individuals, and collectives.

Unfortunately, this is not the world we happen to occupy. However, it seems important to realize that what may appear to be a problem with our values is actually an issue of integrity. It means we can spend less time arguing about which things matter, or how much, and instead channel our considerable intellectual and emotional energies toward reshaping the world in ways that allow us to act upon our most expansive notions of value. A truly just world is also one in which all are empowered to live with integrity.

\section{References}

Alexander, S.M. 2019. Reconciling just preservation. Animal Sentience 27(6).

Bergstrom, B.J. 2019. Just reductionism: In defense of holistic conservation. Animal Sentience 27(8).

Chapman, C.A., and Huffman, M.A. 2018. Why do we want to think humans are different? Animal Sentience 23(1).

Correia Caeiro, C. 2020. Comparative cognition and non-human individuality. Animal Sentience 27(16).

Ditto, P.H., Pizarro, D.A., and Tannenbaum, D. 2009. Motivated moral reasoning. In D.M. Bartels, C.W. Bauman, L.J. Skitka, and D.L. Medin (Eds.), The Psychology of Learning and Motivation, Vol. 50 (pp. 307-338). Academic Press, Burlington.

Dulaney, D.E. 2020. Human-controlled survival of nonhumans. Animal Sentience 27(14).

Graça, J., Calheiros, M.M., and Oliveira, A. 2016. Situating moral disengagement: Motivated reasoning in meat consumption and substitution. Personality and Individual Differences 90: 353-364.

Hayward, M.W., et al. 2019. Deconstructing compassionate conservation. Conservation Biology 33: 760-768.

Johnson, P.J., et al. 2019. Consequences matter: Compassion in conservation means caring for individuals, populations and species. Animals 9: 1115.

Paez, E. 2020. Preserving nature for the benefit of all sentient individuals. Animal Sentience $27(18)$.

Piazza, J., and Loughnan, S. 2016. When meat gets personal, animals' minds matter less: Motivated use of intelligence information in judgments of moral standing. Social Psychological and Personality Science 7: 867-874.

Plumwood, V. 1993. Feminism and the Mastery of Nature. Routledge, New York.

Regan, T. 1983. The Case for Animal Rights. University of California Press, Berkeley. Singer, P. 2011. Practical Ethics, $3^{\text {rd }}$ ed. Cambridge University Press, New York.

Taylor, S. 2018. Interdependent animals: A feminist disability ethic-of-care. In C.J. Adams and L. Gruen (Eds.), Ecofeminism: Feminist Intersections with Other Animals and the Earth (pp. 109126). Bloomsbury, New York. 
Treves, A., Santiago-Ávila, F., and Lynn, W.S. 2019. Just preservation. Animal Sentience 27(1). Uhlmann, E.L., Pizarro, D.A., Tannenbaum, D., and Ditto, P.H. 2009. The motivated use of moral principles. Judgment and Decision Making 4: 476-491.

Vucetich, J.A., Burnham, D., Macdonald, E.A., Bruskotter, J.T., Marchini, S., Zimmerman, A., and Macdonald, D.W. 2018. Just conservation: What is it and should we pursue it? Biological Conservation 221: 23-33.

Wallach, A.D., Bekoff, M., Batavia, C., Nelson, M.P., and Ramp, D. 2018. Summoning compassion to address the challenges of conservation. Conservation Biology 32: 1255-1265.

Warren, K.J. 1990. The power and the promise of ecological feminism. Environmental Ethics 12: 125-146. 


\section{Call for Papers}

\section{Special Issue of the Lournal of Consciousness Studies}

Plant Sentience: Theoretical and Empirical Issues

Guest Editors: Vicente Raja (Rotman Institute of Philosophy, Western University)
Miguel Segundo-Ortin (School of Liberal Arts, University of Wollongong)

In this special issue, we address the issue of plant sentience/consciousness from different disciplines that combine both theoretical and empirical perspectives. Some of the questions to be addressed in the special issue include the following:

- Plants exhibit interesting behaviors; does this entail that they are conscious to some extent?

- What are the requirements for a living organism to be conscious? Do plants meet these requirements?

- What does the possibility of plant sentience/consciousness entail for the study of the evolution of consciousness?

- Is it just a categorical mistake to attribute consciousness to plants?

- Can we talk about different levels or degrees of consciousness?

\section{How to submit?}

\section{Deadline: June 1st, 2020}

Please submit your papers (max. 9000 words including footnotes, references, abstract, etc.) to vgalian@uwo.ca with subject "Paper Special Issue JCS".

For more information, including bibliography and more detailed descriptions of the topics and questions to be addressed in the papers submitted to the special issue, please contact the guest editors at vgalian@uwo.ca (Vicente) or mso693@uowmail.edu.au (Miguel). 